\title{
The Impact of Fast Fashion on Women
}

\author{
Andrea Chang
}

$\mathrm{F}_{\text {cost clothing collections that mimic current lux- }}^{\text {Ast fashion refers to industries that produce low- }}$ ury fashion trends (Joy et al.). It is an industry that has emerged over the past twenty years (Bhardwaj and Fairhurst) due to globalization and neoliberalism, as large corporations have replaced small, primarily female-run apparel businesses (McRobbie) and begun mass producing clothing to retail around the world and outsourcing their production to countries with cheaper labour in order to lower manufacturing costs. Nearly all of the Global North, as well as much of the Global South, wears fast fashion now (Horton 526), and thus is involved with the industry in some capacity. The Global North refers to the developed countries of North America and Europe, while the Global South refers to the often economically disadvantaged nation-states of Latin America, Asia, Africa, and Oceania. Fast fashion is tied to many global challenges, including environmental degradation, globalization, human rights, and feminism. This paper will consider how the constructed gender roles and stereotypes of women uniquely position them to be impacted by the fast fashion industry in terms of both the garment workers who create the clothing and the consumers. This research question is significant because the fast fashion industry has far-reaching negative social and environmental implications and disproportionately impacts women. Additionally, gender is a component that ties together the two major actors in the industry (both the manufacturers and the consumers). There is existing research that provides evidence for female garment workers and female consumers being disproportionately involved with, and affected by, fast fashion (Lam; Khan; McRobbie; Joy et al.; Anastasia; Horton; Ahmed), but little literature exists that analyzes the role that gender construction plays in the inequal- ity of impact. It is important to add to the literature on fast fashion and carefully explore, with nuance, the solutions to the industry's mistreatment of marginalized parties. This paper will approach this research question by first highlighting the problems associated with the fast fashion industry, followed by an analysis of the fashion industry's feminization, the procedures that lead to the exploitative labour of women in sweatshops, and finally the consumers of fast fashion as primarily female, which creates an unjust feminisation of responsibility. This paper will integrate sources from varying academic disciplines, in order to answer the research question with depth. Economic analyses of the fast fashion industry, labour studies and the study of human working rights, feminist theory and gender studies, fashion theory, geography, the study of the legislation of manufacturing clothing, and political and social science will all be drawn on throughout this paper. In this paper, I will argue that constructed gender roles and stereotypes make women especially susceptible to being exploited as garment workers in fast fashion sweatshops, and to consuming fast fashion at a rapid pace and therefore being held responsible for its implications.

Fast fashion has many negative social and environmental consequences, which mainly impact the female garment workers. Critiques of fast fashion have emanated from the academy, industry, popular media forums, and celebrities (Horton 516). Firstly, globalization has brought about systematic inequalities in the fast fashion industry, as garment workers, who are among the world's poorest people, are exploited for the relatively rich to enjoy the luxury of the latest fashion trends (Crewe). The prevalence of the industry also means that there are now on-trend, fashionable pieces that are affordable for low-income people in the Global North to buy. On the surface level, 
more affordable clothing seems like a positive step towards equity. However, where the consumer is paying little, there is someone else paying the price. Bargain price clothing means that consumers are not paying for reasonable wages, working hours, or working conditions for garment workers, meaning that there is a human cost associated with the purchase (Perkins). The business model of fast fashion involves planned obsolescence, in the hallmark late stage of capitalism. Planned obsolescence refers to the practice of planning and designing products with an artificially limited useful life, so that it becomes obsolete after a certain period of time. This practice ensures that consumers have to repurchase items, which bolsters demand. In the fashion industry, this idea manifests in short-lived trends and garments that are of poor quality. Planned obsolescence encourages consumers to keep up with ever-changing fashions by shopping more often, which can only be done if the prices are low enough (Khan). This also has environmental consequences, as there is constant waste being generated because the very nature of fast fashion encourages disposability (qtd. in Joy et al. 275). Additionally, the cheaper materials that are now used in fast fashion items do not decompose and result in faster breakages, which leads consumers to buy more new clothing (Gunner 41). Fast fashion consumes a vast amount of resources, pollutes water, uses toxic chemicals, and produces toxic waste (Gunner 40). The pollution and environmental devastation that is felt from fast fashion most immediately impacts the developing countries in which the clothes are mainly manufactured. Thus, the social implications of the fast fashion industry disproportionately impact women, and the environmental implications disproportionately impact the Global South.

The vast, unnecessary size of global clothing production is abhorrent - it has more than tripled since 2000, and the industry now produces over 150 billion garments a year (Anastasia). The culture of disposable fashion that has permeated the Global North is only possible through the increasingly cheap manufacturing labour in developing countries (Khan). According to the Ethical Fashion Forum (2014), almost three-quarters of the world's clothing exports are made in developing countries often under unfair and unsafe working conditions (Haug and Busch 319). Most of the world's 75 million garment workers are women living in China and Bangladesh (Anas- tasia). They work in sweatshops, under dangerous conditions, often in windowless rooms being poisoned by the fumes from the chemicals used to manufacture and dye clothes (Anastasia). In these countries, wages are among the lowest in the world, there is minimal regulation of safety standards and workers' labour rights, and few opportunities for meaningful unionization or collective action (Khan). Retailers are willing to exploit this cheap labour, and there is a vast supplier network that mediates between these retailers and hundreds of thousands of garment factories. This enables the fast fashion industry to exist in the capacity that it does (Khan).

Haug and Busch have argued that traditionally, ethical fashion focuses on the responsibility of the providers and the consumers of unethical, or fast, fashion items. They claim that such an understanding of the problem of unethical fashion ignores many important aspects, and thus have written a paper in which they identify nine relevant actors that are responsible for the harm caused by the fashion industry (326-327): market regulators (institutions defining laws and regulations for the focal consumer market in relation to production, marketing, use of suppliers, product materials), supplier regulators (institutions defining laws and regulations for the production area in focus - often developing countries), consumers (those exposed to the marketing efforts of the fashion industry and those buying the fashion products), mediators (magazines, news media, forums, activist organizations), designers (those defining the fashion products), marketers (those advertising for and selling the product - retailers), producers (those making the decisions on which fashion items to produce, how to produce them, which markets to target), suppliers (those producing item materials and manufacturing the final products), and workers (the persons employed by the suppliers). They also mention the environment and animals as entities that are affected by the fashion industry without being able to act themselves. I believe that each of these nine actors have the responsibility to change the unethical practices of the fast fashion industry, though not all have the same ability to act. It is also important to recognize that there is widespread change that has to occur in multiple sectors, and responsibility should not be placed onto few, often female, actors when there is much more at play.

It is especially women who suffer from the harm- 
ful implications of the fast fashion industry because it is inherently feminized. In the very development of fast fashion as an industry, it was the women's fashion sector that was accelerated first (Bhardwaj and Fairhurst). Gupta and Gentry's study on the construction of male and female identities when shopping for fashion products provides relevant insights to the feminization of clothing shopping. In Western societies, women, especially those in younger age groups, have traditionally been pressured by sociocultural norms to be concerned about appearance, fashion, and beauty (Gupta and Gentry). Women also tend to be more motivated to purchase clothing than men because they often view it as a more pleasurable activity (Gupta and Gentry). Additionally, women are socialized into being an aesthetically skilled gender, which leads to women who tend to celebrate their skill and prowess in shopping (Gupta and Gentry). Finally, there are "established associations of fashion consumption with irrational and hysterical feminine traits" (Palmer via Beard 457) in popular discourse and academic fashion literature. Thus, it is unsurprising that the fast fashion industry disproportionately harms women in such a large way.

I will argue that women are predominantly employed as garment workers due to sociallyconstructed gender roles and stereotypes, which also make them susceptible to exploitation in these sweatshops. Bangladesh has the cheapest garment workers in the world, who work the longest hours and live in the most crowded and unsanitary slums (Crewe). There, wages have halved in the past 10 years, and children are employed (Crewe). The factories in which fast fashion clothing items are manufactured have dangerous working conditions for the workers (Crewe). Many of these factories are essentially sweatshops, and the garment workers who are trapped, as a result of gender construction in their culture, into working for them are mainly women (Crewe). A sweatshop, as defined by the United States General Accounting Office, is a business that regularly violates both wage or child labour and safety or health laws (Lam 623). A significant amount of fast fashion is manufactured in Bangladesh, with its garment industry being the largest employer of women in the manufacturing sector (Ahmed). Khan suggests that the profitability of the textile and garment industries has long relied upon the exploitation of female labour, and the belief that women are com- pliant and docile, and do not need to earn a living wage (Khan). According to Posner, of New York University's Stern Center for Business and Human Rights, oftentimes these young women in Bangladesh or China are the first in their families to hold jobs. This means that their families are generally eager to get them into the factories as quickly as possible (Anastasia). They risk being fired if they miss a day of work for any reason - including sickness (Anastasia). One example of an inhumanely treated female garment worker is Taslima Aktar, who worked in the Windy Apparels factory in Bangladesh. Her manager refused to give her time off to see a doctor about a persistent fever, but she could not afford to lose her job, so she accepted it. Weeks later, she passed out at work. Her boss sent her immediately back to her sewing machine after she was revived, but shortly after, she died (Anastasia). Overall, there is evidence that these female garment workers are exploited and treated with utter contempt and apathy by the hegemonic masculinity that oversees them.

Ahmed's article explores the social, political, and economic contexts of the Bangladeshi women employed by the garment industry, and thus provides many relevant and useful insights to this paper. In particular, the claims and data in this paragraph have all been originally made by Ahmed, and they will be used to support my point that the social convention that women are expected to uphold in Bangladesh traps them in their sweatshop labour jobs. The Bangladesh garment industry, in its rapid growth at a compound rate of 125 per cent from 1977 to 1991, has provided massive job opportunity for young women in Bangladesh - nearly 200,000 young women appeared in Dhaka city, the capital of Bangladesh, almost overnight. Popular discourse cites this as evidence of a modern environment that allows talent to make it through sheer effort, making the garment industry hailed as the liberator of women. Women are discouraged from many forms of manual labour because of social convention in Bangladesh. However, the industrialists in Bangladesh created socially acceptable work for women in these garment factories, likely because fashion is a feminized industry. Originally, the industrialists persuaded reluctant male guardians to allow women to work by promising that the honour and propriety of the women would be protected in the factory by using spatial segregation of the sexes in the factories. This demonstrates the 
patriarchal social convention present in Bangladesh as agency is stripped from these women - they are not able to make the decision to work on their own. This segregation of the sexes in the factory parallels the gendered wage segregation, with men having jobs with more control and higher wages. Additionally, the risk of sexual harassment is a factor that prevents women from wanting to progress along the ladder. According to literature on the Bangladesh garment industry, employers prefer hiring women because it corresponds with a compliant and low-cost workforce. It is the "docility and dispensability" (Ahmed) of women that makes them so attractive to employers. Additionally, they are only paid $\$ 0.25$ an hour, compared to American garment workers being paid $\$ 7.53$ an hour (in 1999). The threat of imminent layoffs and the exclusivity of the male trade union movement in Bangladesh also prevents women from having a voice in their workplace. Garment factory owners are ever vigilant to the threat of unionization, as they are compelled by the imperative of low labour costs. There are workers selected as informers who turn in their colleagues if union action is being considered. Thus, women are prevented from demanding the national minimum wage through unionization. Ahmed also makes the astute assertion that the women in Bangladesh are socialized to be docile, and the rough and ready politics of the union movement frightens them. The women who work in the garment factories in Bangladesh come from different class backgrounds, so they have varying economic motivations for their employment. Often in Bangladeshi families, the women are poorer and have less control over finances than their male counterparts. Economic need does, in any case, compel women to work at these garment factories - a low wage is better than no wage at all, and it is one of the few accessible and socially acceptable forms of work. In Bangladesh, women have no voice on the factory floor, and so a sweatshop can never be a way out for women. Becoming a garment worker and keeping that job is synonymous with losing voice and staying mute (Ahmed). Thus, specifically in Bangladesh, where a significant amount of fast fashion apparel is manufactured, the social convention of being a woman traps them in their sweatshop labour jobs.

Sweatshop labour exists in the Global North, as well, where similar gender patterns can be observed. The Fair Labour Standards Act in the United States, and similar legislation in other Western countries, regulate minimum wage, maximum hours, and child labour, which makes employers liable to their employees for violations of the Act (Lam 623). However, many employers, especially of labour-intensive industries like the garment industry, persistently violate these laws (Lam 623). The garment industries of fast fashion use small sewing factories that consistently operate under substandard working conditions in immigrant neighbourhoods (Lam 623). In these American sweatshops, the garment workers are most often a Hispanic or Asian female immigrant who moved to an American metropolis with her family in search of economic opportunity (Lam 624). There is drastic wealth disparity between these garment workers and the beneficiary of garment sweatshop labour, who are the apparel manufacturers (Lam 624). With little understanding of English and of their labour rights as employees, these immigrant women are susceptible to exploitation (Lam 626). The influx of immigrants provides a large pool of easily exploited workers to meet the production demand in the United States (Lam 632). Hispanic and Asian women account for nearly the entire labour force in the apparel industry in the United States as of the 1990s (Lam 632). New immigrants are driven to sweatshop employment by their financial needs as well as their lack of English language skills, creating a situation ripe for exploitation (Lam 632).

The consumers of fast fashion are typically understood to be women of the Global North (Khan). Fast fashion brands such as H\&M, Zara, and TopShop are primarily marketed towards young, trend-conscious females, who are implicated in the forms of exploitation practiced by the fast fashion industry (Khan). Oftentimes, women are pitted against other women as consumers of fast fashion. Women who have the financial and cultural capital to shop conscientiously, are characterised as making the right choices, whereas typically younger women with a desire for cheap fast fashion are problematized (Khan). It is often their access to economic resources that affects how ethical or sustainable their practices are (Khan). Fast fashion is also playing to an ever increasing and broadening global audience, because its prices are being reduced (Horton 515). Young women, even those living on low incomes, are now able to regularly and routinely consume and discard fashionable clothing (Horton 516). The role of the Global North con- 
sumer of fast fashion is complex. The fashion industry itself characterizes the consumer desire and demand as the driver of fast fashion (Horton 516). However, many critics instead argue that it is the system that positions consumers to be embroiled in superfluous consumption that serves the interests of capitalist production (Horton 516). Horton argues that the agency of even the most well-meaning and mindful consumer is corrupted by fast fashion. This is because the market is flooded with cheap clothes, so individual consumers are incapable of translating their ethical attitudes into ethical behaviours (Horton 516). Joy et al. conducted a study on this very idea and concluded that fast fashion consumers often share a concern for environmental issues, while still engaging in consumer patterns antithetical to ecological best practices. Oftentimes consumers apply strategies to justify unethical purchases, including ignoring information about production processes and denying responsibility for the victim (the sweatshop workers and the environment) (Haug and Busch 323). Additionally, consumers may also be unwilling to adopt more ethical or sustainable practices because they feel physically and culturally distanced from the problems in focus (Haug and Busch 324).

Fast fashion is a complex and geographically dispersed system in which Haug and Busch's nine actors, as referenced earlier, are implicated. The scale and the complexity of the fast fashion industry is what makes intervention or a solution difficult. Khan, in her article on women in fast fashion activism, provides many important insights on the problem with positioning the female consumer as the solution to the fast fashion industry. I will detail Khan's most relevant points in this paragraph to support my argument that the responsibility that falls on women in particular to stop the harm of the fast fashion industry is harmful and unfair. Many academics have only proposed a single distinctly individual and neoliberal solution, which is for consumers to change their personal shopping habits. While women are usually both the instigators and the targets of ethical fashion campaigns, it is nearly always a privileged, white woman who is the agent of change. Many solutions to the fast fashion dilemma emphasize the agency of the privileged fashion consumer, and the voicelessness of sweatshop workers. However, it is important to recognize that there are forms of activism that do exist in these garment producing coun- tries. For example, following the Rana Plaza garment factory collapse in 2013, widespread protests among Bangladeshi garment workers led to an increase in minimum wage. Additionally, although workers' efforts to unionize are often met with physical and sexual violence, some women still participate in collective action to place demands on factory owners and managers. It is problematic for popular discourse to dismiss these women's vital and continuing role in reforming the garment industry, in favour of focusing on the self-reflective, stylish fashion consumer as the solution. Many fast fashion critiques use a neoliberal activist strategy in which the individual consumer, characterised as a young woman, is blamed for the unsustainable and exploitative nature of the fashion industry. Although in most recent academic critiques, corporations are still held somewhat responsible, the consumer has been more responsible than ever before - both for her materialistic desires but also for changing into a more conscious shopper. Although consumer movements and boycotts have been advocated as important forms of anticorporate activism, this new discourse gives us a more serious moral weight attached to our individual fashion choices. I agree with Khan in her argument that the fast fashion critique sets out to be a structural one, but it is ultimately distilled into a neoliberal one, which asks us to reform and regulate ourselves, and favours the women who have the cultural and economic resources to do so.

In this section, I will draw on economic analyses of the fast fashion industry, critical studies on current global challenges, as well as feminist theory to present the idea that the female consumer of fast fashion is unreasonably expected to stop the harmful behaviour of the industry. For example, Horton argues that both scholarly and popular discourses position young women as "the main protagonists in the frenetic consumer culture of twenty-first century fashion" (517). She argues that these discourses simultaneously hold these young women as most responsible for the damage and destruction caused by the fast fashion industry, leading to the young women self-identifying as such. For example, Micheletti and Stolle argue that consumer action in the anti-sweatshop movement is not particularly effective, but is significant because it is more than corporations and the government are doing. Horton argues that the era of fast fashion represents a particularly intense version of both the 
feminisation of consumption and the feminisation of responsibility and obligation. Khan's idea of neoliberalism being positioned as the solution to the problems of the fast fashion industry, as highlighted in the previous paragraph, might explain what Horton means by the feminisation of responsibility. Haug and Busch argue that consumer responsibility for changing the fast fashion industry is limited because the target market is teenagers and young adults, who often do not have the financial resources to buy the more expensive and ethically produced fashion items, and are often not among the most knowledgeable consumers (331). They conclude, however, after a detailed study, that the most important actor that would have the most impact in changing the fast fashion industry into one that is more ethical and sustainable is the high fashion industry - if they should make unethical clothing unfashionable, then fast fashion brands will have no choice but to change their production methods in their imitation of high fashion (334). Thus, the feminisation of responsibility placed upon the consumer is unfair when they have a more limited role than what most literature suggests.

Throughout this paper, I have looked at the extensive harm that the fast fashion industry inflicts on various groups of people and the environment. I will argue that it is the large fast fashion corporations, as the manufacturers of clothing that benefit from the system. It is so difficult to solve the problems of the fast fashion industry precisely because the corporations, who have the most power to change their own actions, derive so much profit from their practices. Lam also claims that the true beneficiary of the sweatshop system in the apparel industry is the manufacturer. As such, he claims that they should be held accountable for the problems that plague the industry (627). The sweatshop system prevails because manufacturers find substantial savings in using lowpriced labour contracts rather than maintaining their own sewing and assembly labour force (Lam 631). Contract labour gives manufacturers a virtually unlimited supply of labour, without any responsibility to the labour force (Lam 631). It allows the manufacturer to calculate production costs with complete disregard for the costs and circumstances of labour (Lam 631). A root issue with the fast fashion industry is that the manufacturers are looking to cut costs with no care for the harmful implications of their ac- tions. According to Frankental, corporate social responsibility is imperative and must change so that it is meaningfully a part of major corporations (18). Although his research refers to major corporations generally, it can certainly be applied to the corporate giants of the fast fashion world. He argues that corporate social responsibility must change to embrace all stakeholders of the company, be reinforced by changes in company law related to governance, be rewarded by financial markets, have a clear definition which relates to the goals of social and ecological sustainability, have its implementation be benchmarked and audited, be open to public scrutiny, have compliance mechanisms in place, and be totally embedded in the corporation.

The ethical fashion industry is attempting to become a replacement or alternative to the fast fashion industry. The most frequently cited definition of ethical fashion is the one by Joergens (2006), which is that the governing principle of ethical fashion is "fashionable clothes that incorporate fair trade principles with sweatshop-free labour conditions while not harming the environment or workers by using biodegradable and organic cotton". Ethical fashion tends to be more expensive than fast fashion, but it is understood as an investment worth making if one is serious about being a responsible consumer (Khan). However, this can be problematic in that buying into ethical fashion requires economic capital which not all women can access. Khan argues that the critiques of fast fashion and disposable consumer culture risk idealizing a conscientious consumer who is willing to pay more for their clothes. In doing so, it oversimplifies the kinds of ethical calculations that actually shape our everyday shopping choices (Khan). Consumption is a complex activity; for example, consumption in a family is a practice of care and responsibility that complicates ethical decision-making (Khan). There is a 'rational choice model' of consumption that assumes that consumers will shop more responsibly if they simply have better access to knowledge about the products and the effects of their consumption practices (Khan); however, this does not account for the messy moral negotiations that take place if one is low-income, like a single mother shopping for her children on a tight budget (Khan). Ultimately, affordability is a significant constraint on consumption choice. Additionally, ethical consumption is a process that calls for the consumer to be concerned with 
future generations, and with garment workers around the world. However, this contradicts the self-interest of consumers - they would rather satisfy their shortterm desires and buy less expensive rather than more expensive clothing (Haug and Busch 324). Although the market for ethical fashion is growing, it currently constitutes just 0.4 per cent of the UK market, and environmentally friendly apparel only accounts for about 1 per cent of the total global apparel market (Haug and Busch 319).

Thus, many academics argue that there are alternate solutions to the fast fashion industry, and alternate actors that must be held accountable for the plight of the industry other than the young, female consumer. Although I believe that the consumer holds some responsibility for the harm that the fast fashion industry causes, I think that the most pragmatic and impactful solution lies outside of the consumer and requires multiple actors. This is because oftentimes the fast fashion consumer has little choice in her purchase habits, because of the high price tag associated with ethical fashion and limited knowledge on ethical fashion. Instead, I think governments and regulators have responsibility to regulate working conditions and maintain transparency on the processes of clothing production. Additionally, fast fashion manufacturers, as the main beneficiaries, must also assume responsibility for the harm that the industry causes. Lastly, the media and high fashion have power to make ethical clothing fashionable, and should do so. I believe that it is ultimately up to the fast fashion manufacturer to change its practices, but realistically they will not do so without the pressure of governments, regulators, media, and high fashion because, for the manufacturer, the benefit outweighs the harm.

In conclusion, the constructed gender roles and stereotypes of women position them to be uniquely impacted by the fast fashion industry because of the feminization of the fashion industry as a whole. They are disproportionately employed in the sweatshops of the garment industry, and also are mainly targeted as the consumers of fast fashion. However, because of the different levels of privilege that consumers and garment workers hold - although they are both affected by the fast fashion industry more so than their male counterparts - gender plays two different roles in these two different situations. Ultimately, many modern fast fashion critiques take a neoliberal stance in putting the responsibility on these young fast fashion consuming women to stop the fast fashion industry. However, alternate literature suggests that other actors have immense responsibility that is often overlooked. Thus, although these relatively privileged young women do have some responsibility in the horrors of the fast fashion industry, the feminization of responsibility for the practices of the industry are unfair. When a highly feminized industry like the fast fashion one becomes problematic, the responsibility for positive change is also placed upon females. The switch to ethical and sustainable fashion as the primary, and only, type of clothing to purchase is imperative. However, this switch should not only be the consumers' burden, but rather that of the fashion industry as a whole.

\section{Author Biography}

Andrea Chang is a student in the Arts \& Science Program at McMaster University. The interdisciplinary thinking and perspectives that she has learned from this program have allowed her to make connections that align with the goals of JIRR. She changed her personal shopping habits when she became aware of the far-reaching negative implications of the fast fashion industry, to attempt to stop her contribution to the problem. In her Inquiry of Global Challenges class, she was given the opportunity to thoroughly investigate and write about any global challenge of her choice. She was excited to explore her personal interest in fast fashion in an academic context and contribute to the discussion surrounding it. She is incredibly grateful to the editorial team at JIRR for the opportunity to share her work on such an important topic! 


\section{Works Cited}

Ahmed, Fauzia Erfan. "The Rise of the Bangladesh Garment Industry: Globalization, Women Workers, and Voice." NWSA Journal, 22 June 2004, https://link-galegroup-com.libaccess.lib.

mcmaster.ca/apps/doc/A120353243/AONE?sid=lms.

Anastasia, Laura. "The Real Cost of CHEAP FASHION: Many of our trendy, inexpensive clothes are made in places like Bangladesh, where workers-including children-toil under conditions that may shock you." New York Times Upfront, 4 Sept. 2017, p. 8+. Gale OneFile: Contemporary Women's Issues, https://link.gale.com/apps/doc/A512374636/CWI?u=ocul_mcmaster\&sid=CWI\&xid=5b1afeab. Accessed 3 Dec. 2019.

Beard, Nathaniel Dafydd. "The Branding of Ethical Fashion and the Consumer: A Luxury Niche or MassMarket Reality?" Fashion Theory, vol. 12, no. 4, Dec. 2008, pp. 447-67. Taylor and Francis+NEJM, doi:10.2752/175174108X346931.

Bhardwaj, Vertica, and Ann Fairhurst. "Fast Fashion: Response to Changes in the Fashion Industry." The International Review of Retail, Distribution and Consumer Research, vol. 20, no. 1, Feb. 2010, pp. 165-73. Taylor and Francis+NEJM, doi:10.1080/09593960903498300.

Crewe, Louise. "Ugly Beautiful?: Counting the Cost of the Global Fashion Industry." Geography, vol. 93, no. 1, 2008, pp. 25-33. JSTOR.

Frankental, Peter. 'Corporate Social Responsibility - a PR Invention?" Corporate Communications: An International Journal, vol. 6, no. 1, 2001, pp. 18-23.

Gunner, Alan. "Fast Fashion and Its Impact on the Environment." Logistics 8 Transport Focus, vol. 21, no. 5, May 2019, pp. 40-41.

Gupta, Shipra, and James W. Gentry. "Construction of Gender Roles in Perceived Scarce Environments - Maintaining Masculinity When Shopping for Fast Fashion Apparel." Journal of Consumer Behaviour, vol. 15, no. 3, May 2016, pp. 251-260. EBSCOhost, doi:10.1002/cb.1565.

Haug, Anders, and Jacob Busch. "Towards an Ethical Fashion Framework." Fashion Theory, vol. 20, no. 3, May 2016, pp. 317-39. Taylor and Francis+NEJM, doi:10.1080/1362704X.2015.1082295.

Horton, Kathleen. "Just Use What You Have: Ethical Fashion Discourse and the Feminisation of Responsibility." Australian Feminist Studies, vol. 33, no. 98, Oct. 2018, pp. 515-29. Taylor and Francis+NEJM, doi:10.1080/08164649.2019.1567255.

Joy, Annamma, et al. "Fast Fashion, Sustainability, and the Ethical Appeal of Luxury Brands." Fashion Theory, vol. 16, no. 3, Sept. 2012, pp. 273-95. Taylor and Francis+NEJM, doi:10.2752/175174112X13340749707123.

Khan, Rimi. "Doing Good and Looking Good: Women in "Fast Fashion" Activism" Women E⿱ Environments International Magazine, iss. 96/97, pp. 7-9. https://search.proquest.com/docview/1882372155/fulltext/4C75E032377040B5PQ/1?accountid=12347. Accessed 25 Nov. 2019.

Lam, Leo L. "Designer Duty: Extending Liability to Manufacturers for Violations of Labor Standards in 
Garment Industry Sweatshops." University of Pennsylvania Law Review, vol. 141, no. 2, 1992, pp. 623-67. JSTOR, JSTOR, doi:10.2307/3312361.

Perkins, Michael, et al. "Scholars' Roundtable Presentation." Dress, vol. 44, no. 2, July 2018, pp. $133-51$. Taylor and Francis+NEJM, doi:10.1080/03612112.2018.1507345.

McRobbie, Angela. "Fashion Culture: Creative Work, Female Individualization." Feminist Review, no. 71, 2002, pp. 52-62. JSTOR, www.jstor.org/stable/1396021.

Micheletti, Michele, and Dietlind Stolle. "Mobilizing Consumers to Take Responsibility for Global Social Justice." The Annals of the American Academy of Political and Social Science, vol. 611, 2007, pp. 157-75. JSTOR. 